\title{
A CLINICAL STUDY TO EVALUATE THE EFFECTS OF INTRATHECAL DEXMEDETOMIDINE 10 MCG ON LOW DOSE HYPERBARIC 0.5\% BUPIVACAINE (5 MG) FOR SADDLE BLOCK ANAESTHESIA IN ADULT PATIENTS POSTED FOR ELECTIVE PERIANAL SURGERIES
}

\author{
Thuraganur Kapanigowda Shashikala1, Gowda Ashwathappa Prathibha² \\ ${ }^{1}$ Associate Professor, Department of Anaesthesiology, K. R. Hospital, Mysore Medical College and Research Institute, Mysore. \\ 2Junior Resident, Department of Anaesthesiology, K. R. Hospital, Mysore Medical College and Research Institute, Mysore.
}

\begin{abstract}
AIMS AND OBJECTIVES

Saddle block anaesthesia is most commonly used technique for perineal surgeries, i.e. haemorrhoids, fissure-in-ano, etc., as it is most economical and easy to administer. Spinal anaesthesia by bupivacaine may be too short for providing postoperative analgesia. Hence, various adjuvants have been used with Local anaesthetics to provide good intraoperative anaesthesia and to prolong postoperative analgesia. The aim of our study was to evaluate the effects of intrathecal administration of dexmedetomidine $10 \mu \mathrm{g}$ on low dose bupivacaine $0.5 \%$ ( $5 \mathrm{mg}$ ), to know the onset and duration of sensory and motor blockade, the haemodynamic effects, duration of analgesia and the occurrence of side effects.
\end{abstract}

\section{METHODOLOGY}

This prospective randomized double blind study included 60 patients. Patients were randomly allocated into two groups of 30 patients each. Group D received $5 \mathrm{mg}$ of $0.5 \%$ hyperbaric with dexmedetomidine $10 \mu \mathrm{g}(0.5 \mathrm{~mL})$ and Group N received $5 \mathrm{mg}$ of $0.5 \%$ hyperbaric bupivacaine with $0.5 \mathrm{~mL}$ of normal saline. The onset of sensory and motor block, haemodynamic effects, duration of analgesia and occurrence of side effects were noted.

\section{RESULTS}

The mean time taken for the onset of sensory block was $6.36 \pm 1.2$ min and $8.23 \pm 1.7$ significantly rapid with D Group compared to group N. The total duration of analgesia $(360 \pm 15 \mathrm{~min}$ and $210 \pm 30 \mathrm{~min}$ in Group D and Group N respectively, $\mathrm{P}<0.000)$ and time to first rescue analgesic $(370.85 \pm 15 \mathrm{~min}, 230.8 \pm 15 \mathrm{~min}$ in Group D and Group N respectively, $\mathrm{P}<0.001)$ were increased significantly by addition of dexmedetomidine without significant motor block and with minimal side effects.

\section{CONCLUSION}

Dexmedetomidine added intrathecally for saddle block had favourable effects on onset of sensory and total duration of analgesia and rescue analgesia.

\section{KEYWORDS}

Spinal, Dexmedetomidine, Surgeries.

HOW TO CITE THIS ARTICLE: Shashikala TK, Prathibha GA. A clinical study to evaluate the effects of intrathecal dexmedetomidine $10 \mathrm{mcg}$ on low dose hyperbaric $0.5 \%$ bupivacaine $(5 \mathrm{mg}$ ) for saddle block anaesthesia in adult patients posted for elective perianal surgeries. J. Evolution Med. Dent. Sci. 2016;5(45):2801-2804, DOI: 10.14260/jemds/2016/654

\section{INTRODUCTION}

Saddle block anaesthesia is most commonly used technique for perineal surgeries, i.e. haemorrhoids, fissure-in-ano, etc., as it is most economical and easy to administer. Low dose local anaesthetics can limit the block level and induce rapid recovery from anaesthesia. The recommended dose for anorectal surgery is 1-1.5 mL of hyperbaric $0.5 \%$ bupivacaine or $5 \%$ lidocaine. These patients after perineal surgeries will have severe pain if only local anaesthetics are used, as the duration of action of local anaesthetics will not be prolonged to manage post-operative analgesia. Various adjuvants have been used along with local anaesthetic agents

Financial or Other, Competing Interest: None.

Submission 21-04-2016, Peer Review 18-05-2016,

Acceptance 21-05-2016, Published 04-06-2016.

Corresponding Author:

Dr. Thuraganur Kapanigowda Shashikala,

Associate Professor,

Department of Anaesthesiology,

Stone Building, K. R. Hospital,

Mysore Medical College and Research Institute,

Mysore.

E-mail:drshi72@yahoo.com

DOI: $10.14260 /$ jemds $/ 2016 / 654$ to prolong the block duration with reduced rate of adverse effects.

Alpha-2( $\alpha 2)$ adrenergic receptor agonists like clonidine and dexmedetomidine have been the focus of interest as adjuvants to intrathecal local anaesthetics due to their sedative, analgesic, perioperative sympatholytic and haemodynamic stabilizing properties. ${ }^{1}$

Dexmedetomidine (DXM) is an S-enantiomer of medetomidine with a highly selective $\alpha_{2}$ adrenergic receptor agonistic activity with a relatively high ratio of $\alpha_{2} / \alpha_{1}$ activity (1620:1) compared to clonidine (220:1). ${ }^{2}$ Dexmedetomidine has been safely used as an adjuvant for subarachnoid block in urological, orthopaedic and lower abdominal surgical procedures. As adjuvant neuraxial administration is the appropriate route to dexmedetomidine, because the analgesic effect of $\alpha 2$ agonists mostly occurs at spinal level, binding to spinal cord $\alpha 2$ adrenergic receptor.

Though intrathecal Dexmedetomidine has been used for various surgeries as an adjuvant to local anaesthetics, its use for saddle block is not extensively studied.

The present study is designed to evaluate the effects of addition of Dexmedetomidine $(10 \mu \mathrm{g})$ to hyperbaric 
bupivacaine $0.5 \%$ for saddle block anaesthesia in terms of onset and duration of sensory block, post-operative analgesia.

\section{METHODOLOGY}

After Institutional Ethical Committee approval and informed consent, 60 patients in the age group between 18 and 50 years belonging to ASA class I and II undergoing elective haemorrhoidectomy under saddle block were randomly allocated into two equal groups using shuffled sealed opaque envelope technique. Patients with known hypersensitivity to local anaesthetics or dexmedetomidine, subjects having any absolute contraindications for spinal anaesthesia like raised intracranial pressure, severe hypovolaemia, bleeding diathesis, local infection, patient refusal, comorbidities like diabetes, hypertension, epilepsy, morbid obesity, pregnant women were excluded from the study. All patients were premedicated on the night before surgery with Tablet Ranitidine $150 \mathrm{mg}$ and were kept nil per oral 6 hours for solid food and 2 hours for clear fluids. On arrival to operation theatre, IV access was taken using 18G cannula on non-dominant hand.

Patients were connected to multi-parameter monitor having Electrocardiography (ECG), Non-Invasive Blood Pressure (NIBP) and arterial pulse saturation ( $\left.\mathrm{SPO}_{2}\right)$. Under aseptic precautions, lumbar puncture was performed at the level of L2-L3/L3-L4 through a midline approach using 25G Quincke's spinal needle and study drug was injected after confirmation of needle tip in the subarachnoid space by clear and free flow of Cerebrospinal Fluid. Patients were kept in sitting position for 5 minutes and then brought to supine posture. After 10 minutes, patients were placed in lithotomy posture.

Dexmedetomidine for intrathecal use was prepared by diluting $1 \mathrm{~mL}$ (containing $100 \mu \mathrm{g}$ ) to $5 \mathrm{~mL}$ with normal saline; $0.5 \mathrm{~mL}$ of this diluted solution (containing $10 \mu \mathrm{g}$ ) was taken using $1 \mathrm{~mL}$ insulin syringe and added to syringe containing 1 $\mathrm{mL}$ of $0.5 \%$ hyperbaric bupivacaine, which was given for group D patients. For Group $\mathrm{N}$ patients, $0.5 \mathrm{~mL}$ of normal saline taken in insulin syringe added to $1 \mathrm{~mL}$ of $0.5 \%$ hyperbaric bupivacaine. Both the test drugs were prepared by senior anaesthesiologist under sterile technique who was not involved in the study. Saddle block anaesthesia for all patients in study was given by the same anaesthesiologist who was the observer too. Thus both the observer and subjects were blinded to the study drugs.

Sensory blockade was tested using pinprick method with a blunt 27G hypodermic needle every 15 seconds till the onset of sensory blockade and thereafter at 2 mins intervals till the maximum level of sensory blockade was achieved. Time taken for sensory block to reach L1 dermatome and motor block were noted. Pain was assessed by Verbal Rating Score (VAS) at $1^{\text {st }}, 2^{\text {nd }}, 4^{\text {th }}$ and $6^{\text {th }}$ hours post-operatively, where patients were given a scale marked from 0 to 10 and were asked to mark the degree of pain experienced ranging from 'No pain' at 0 to 'Maximum pain' at 10 point. At VRS $>4$, Inj. diclofenac $75 \mathrm{mg}$ IM was given as rescue analgesic and study ended. Duration of analgesia measured from the time of intrathecal injection to the first request of analgesia [VRS $>4$ ] was monitored. Sedation was assessed using Ramsay Sedation Score (RSS) and baseline sedation score was noted. Incidence of side effects like nausea, vomiting, hypotension, bradycardia were noted.

The statistical analysis of data was done by using Statistical Package for Social Science (SPSS) evaluation version 20. Data were expressed as either mean and standard deviation or numbers and percentages. The demographic data of the patients were studied for each of the two groups. Continuous covariates (Age, duration of surgery, height, weight) were compared using Analysis Of Variance (ANOVA). For categorical covariates (Gender, ASA class), Chi-square test was used with $\mathrm{p}$-value reported at $95 \%$ confidence interval. For the time to reach $\mathrm{L} 1$ dermatome, Bromage, time taken to rescue analgesia ANOVA test followed by Tukey's multiple post-hoc test was used. The level of significance used was $\mathrm{p}<0.05$

\section{RESULTS}

The groups were comparable with respect to age, weight, height, sex distribution and operative time. The onset of sensory block was $6.36 \pm 1.2 \mathrm{~min}$ and $8.23 \pm 1.7 \mathrm{~min}$ in group $\mathrm{D}$ and group $\mathrm{N}$ respectively, $\mathrm{p}<0.000$. All the patients achieved sensory level of at least S1 dermatome block and motor blockade of modified Bromage score 0, that is, no detectable weakness of lower limb when they were made supine after completion of 5 min after subarachnoid block; however, in 4 patients motor blockage of Bromage score 1 was noticed. There was no difference between Group D and $\mathrm{N}$ in the maximum level of blocks achieved (T10). In all the patients, maximum sensory level recorded at 20 min was similar to or higher than the sensory level recorded immediately postoperatively. Time for regression of sensory level to S1 $(360 \pm 15 \mathrm{~min}$ and $210 \pm 30 \mathrm{~min}$ in Group D and Group N respectively, $\mathrm{P}<0.000$ ) and time for first administration of analgesic (370.85 \pm 15 min, $230.8 \pm 15$ min in Group D and Group N, respectively, $\mathrm{P}<0.001$ ) were clinically and statistically prolonged in Group D. The duration of motor blockade noticed in four patients (180 min in Group D, which were not significant. The post-operative VAS scores were higher in Group N than in Group D after 180 min in the postoperative period. Intraoperative HR and BP were comparable between the two groups. All patients in both the groups were calm and cooperative and no undue sedation (Sedation score $>3$ ) was observed intra-operatively. The incidence of side effects was not statistically significant in both the groups.

Time of onset of sensory blockade was $6.36 \pm 1.2 \mathrm{~min}$ and $8.23 \pm 1.7$ min with group $\mathrm{D}$ and $\mathrm{C}$ respectively.

\begin{tabular}{|c|c|c|c|}
\hline $\begin{array}{c}\text { Duration of Analgesia } \\
\text { in Minutes }\end{array}$ & Group-D & Group-C & P value \\
\hline Mean \pm SD & $6.36 \pm 1.2$ & $8.23 \pm 1.7$ & 0.000 \\
\hline \multicolumn{3}{|c|}{ Table 1: Time of Onset of Sensory Block } \\
\hline
\end{tabular}

There was significant difference between two groups, group D has faster onset of sensory blockade compared to Group N, $\mathrm{p}<0.000$. 


\begin{tabular}{|c|c|c|c|c|c|}
\hline & Group D & Group C & \\
\hline \multirow{12}{*}{ Analgesia } & \multirow{2}{*}{ L1 } & Count & 19 & 6 & 25 \\
\hline & & \% within Grp & $63.3 \%$ & $20.0 \%$ & $41.7 \%$ \\
\hline & \multirow{2}{*}{ S4 } & Count & 3 & 4 & 7 \\
\hline & & \% within Grp & $10.0 \%$ & $13.3 \%$ & $11.7 \%$ \\
\hline & \multirow{2}{*}{ S3 } & Count & 5 & 10 & 15 \\
\hline & & \% within Grp & $16.7 \%$ & $33.3 \%$ & $25.0 \%$ \\
\hline & \multirow{2}{*}{$\begin{array}{c}\mathrm{T} 1 \\
0 \\
\end{array}$} & Count & 3 & 1 & 4 \\
\hline & & \% within Grp & $10.0 \%$ & $3.3 \%$ & $6.7 \%$ \\
\hline & \multirow{2}{*}{ S2 } & Count & 0 & 2 & 2 \\
\hline & & \% within Grp & $0.0 \%$ & $6.7 \%$ & $3.3 \%$ \\
\hline & \multirow{2}{*}{ S1 } & Count & 0 & 7 & 7 \\
\hline & & \% within Grp & $0.0 \%$ & $23.3 \%$ & $11.7 \%$ \\
\hline \multirow{2}{*}{\multicolumn{2}{|c|}{ Total }} & Count & 30 & 30 & 60 \\
\hline & & \% within Grp & $100.0 \%$ & $100.0 \%$ & $100.0 \%$ \\
\hline \multicolumn{6}{|c|}{ Table 2: Maximum Levels of Sensory Blockade } \\
\hline
\end{tabular}

\begin{tabular}{|c|c|c|c|c|c|}
\hline \multicolumn{7}{|c|}{ Group Statistics } \\
\hline & Grp. & N & Mean & $\begin{array}{c}\text { Std. } \\
\text { Deviation }\end{array}$ & $\begin{array}{c}\text { Std. Error } \\
\text { Mean }\end{array}$ \\
\hline $\begin{array}{c}\text { Dura } \\
\text { analgesia }\end{array}$ & DXM & 30 & 360 & .36636 & .06689 \\
\cline { 2 - 6 } & Normal & 30 & 210 & .53738 & .09811 \\
\hline \multicolumn{7}{|c|}{ Table 3: Duration of Analgesia } \\
\hline
\end{tabular}

Duration of analgesia between two groups, $360 \pm 15 \mathrm{~min}$ and $210 \pm 30$ min with group $D$ and $C$ respectively. There was significant difference between two groups with prolonged duration of postoperative analgesia with group D compared to group $\mathrm{N}$.

\section{Mean Heart Rate in bpm at Various Intervals in Minutes}

\begin{tabular}{|c|c|c|}
\hline $\begin{array}{c}\text { HR in bpm at Various } \\
\text { Intervals (Minutes) }\end{array}$ & Group N & Group D \\
\hline Basal & $76.0 \pm 9.823$ & $79.8 \pm 9.280$ \\
\hline 0 & $75.7 \pm 9.526$ & $79.4 \pm 8.876$ \\
\hline 2 & $77.1 \pm 10.868$ & $79.4 \pm 7.713$ \\
\hline 4 & $75.7 \pm 9.568$ & $79.3 \pm 8.922$ \\
\hline 6 & $75.7 \pm 9.952$ & $77.8 \pm 9.193$ \\
\hline 8 & $76.2 \pm 10.389$ & $77.8 \pm 8.016$ \\
\hline 10 & $76.7 \pm 9.824$ & $76.0 \pm 9.349$ \\
\hline 15 & $76.3 \pm 9.223$ & $76.6 \pm 10.118$ \\
\hline 20 & $74.8 \pm 7.627$ & $76.2 \pm 10.138$ \\
\hline 25 & $75.0 \pm 7.650$ & $76.4 \pm 9.261$ \\
\hline 30 & $75.1 \pm 7.519$ & $75.6 \pm 7.342$ \\
\hline 35 & $75.0 \pm 6,826$ & $75.0 \pm 5.376$ \\
\hline \multicolumn{2}{|c|}{ Table 4: Heart Rate } \\
\hline
\end{tabular}

There was no significant difference in the heart rate in between two groups.

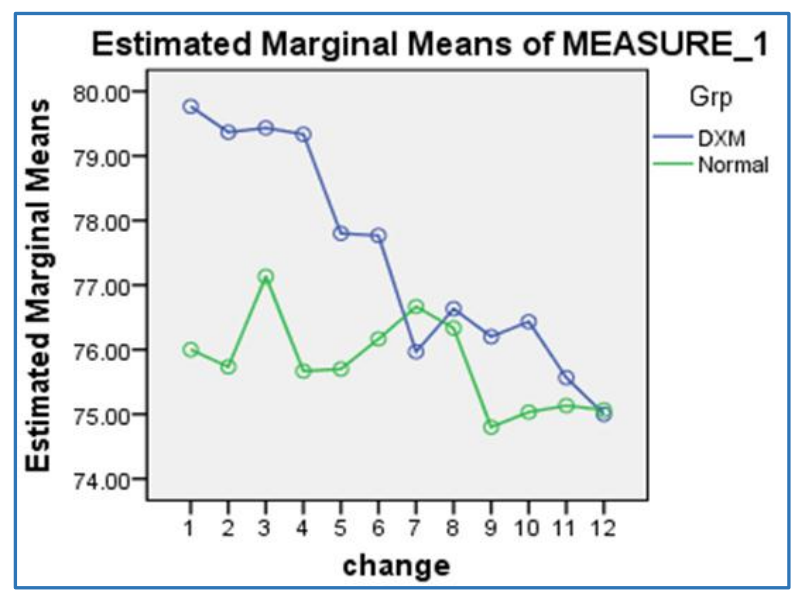

\begin{tabular}{|c|c|c|}
\hline $\begin{array}{c}\text { SBP at Various } \\
\text { Intervals }\end{array}$ & Group-C & Group-D \\
\hline Basal & $124.1 \pm 10.823$ & $122.6 \pm 10.404$ \\
\hline 0 & $122.8 \pm 8.849$ & $123.5 \pm 9.247$ \\
\hline 2 & $122.2 \pm 8.772$ & $122.9 \pm 8.943$ \\
\hline 4 & $119.8 \pm 7.912$ & $122.0 \pm 8.845$ \\
\hline 6 & $119.7 \pm 6.762$ & $122.0 \pm 10.327$ \\
\hline 8 & $120.2 \pm 6.623$ & $121.5 \pm 10.295$ \\
\hline 10 & $118.4 \pm 6.856$ & $121.4 \pm 9.733$ \\
\hline 15 & $117.3 \pm 6.507$ & $120.3 \pm 9.667$ \\
\hline 20 & $117.6 \pm 6.404$ & $121.0 \pm 9.812$ \\
\hline 25 & $118.9 \pm 6.625$ & $121.8 \pm 7.851$ \\
\hline 30 & $119.6 \pm 4.854$ & $121.8 \pm 7.937$ \\
\hline 35 & $120.4 \pm 4.530$ & $118.5 \pm 19.659$ \\
\hline \multicolumn{3}{|c|}{ Various Interval in mmHg } \\
\hline \multicolumn{2}{|c|}{} \\
\hline \multicolumn{2}{|c|}{ Table 5: Mean Systolic Blood Pressure at } \\
\hline
\end{tabular}

\begin{tabular}{|c|c|c|}
\hline DBP at Various Intervals & Group-C & Group-D \\
\hline Basal & $78.3 \pm 6.809$ & $80.7 \pm 5.299$ \\
\hline 0 & $78.7 \pm 6.977$ & $81.2 \pm 6.206$ \\
\hline 2 & $79.8 \pm 6.226$ & $81.0 \pm 6.327$ \\
\hline 4 & $79.5 \pm 6.447$ & $80.3 \pm 6.147$ \\
\hline 6 & $79.2 \pm 6.071$ & $81.1 \pm 5.944$ \\
\hline 8 & $79.1 \pm 6.511$ & $78.4 \pm 6.095$ \\
\hline 10 & $79.0 \pm 6.729$ & $80.0 \pm 4.944$ \\
\hline 15 & $78.1 \pm 5.741$ & $78.7 \pm 5.785$ \\
\hline 20 & $78.0 \pm 5.696$ & $78.3 \pm 6.362$ \\
\hline 25 & $77.5 \pm 5.450$ & $79.2 \pm 5.027$ \\
\hline 30 & $77.9 \pm 5.406$ & $79.7 \pm 5.688$ \\
\hline 35 & $78.7 \pm 4.852$ & $79.4 \pm 5.757$ \\
\hline \multicolumn{3}{|c|}{$\begin{array}{c}\text { Table 6: Mean Diastolic Blood Pressure at } \\
\text { Various Interval in } \mathrm{mmHg}\end{array}$} \\
\hline
\end{tabular}

\begin{tabular}{|c|c|c|c|c|}
\hline \multirow{2}{*}{$\begin{array}{c}\text { Adverse } \\
\text { Effect }\end{array}$} & \multicolumn{2}{|c|}{ Group-N } & \multicolumn{2}{|c|}{ Group-D } \\
\hline & $\begin{array}{c}\text { No. of } \\
\text { pts. }\end{array}$ & Percentage & $\begin{array}{c}\text { No. of } \\
\text { pts. }\end{array}$ & Percentage \\
\hline Bradycardia & 0 & $0.0 \%$ & 1 & $3.3 \%$ \\
\hline Hypotension & 0 & $0.0 \%$ & 1 & $3.3 \%$ \\
\hline Vomiting & 0 & $0.0 \%$ & 0 & $0.0 \%$ \\
\hline \multicolumn{5}{|c|}{ Table 7: Adverse Effects } \\
\hline
\end{tabular}

The heart rate, blood pressure, respiratory rate assessed at various time interval showed no statistically significant differences. Episodes of hypotension and bradycardia were treated with Inj. mephentermine $6 \mathrm{mg}$ and Inj. atropine 0.3 mg respectively.

\section{DISCUSSION}

Dexmedetomidine has been used as an intrathecal adjuvant for spinal anaesthesia in various doses from 3-15 $\mu$ g. ${ }^{3}$ Various clinical studies using dexmedetomidine as an adjuvant with bupivacaine have found to be safe without producing any neurological deficit.4,5,6 Dexmedetomidine is more specific to $\alpha 2$ adrenergic receptor and recently introduced in India.

Halder S et al,7 conducted a study with different doses of intrathecal dexmedetomidine, they concluded that addition of $10 \mu \mathrm{g}$ in comparison to $5 \mu \mathrm{g}$ dexmedetomidine to hyperbaric bupivacaine $0.5 \%$ more efficiently hastens the onset and prolongs the duration of sensory and motor blockade and reduces the requirement of rescue analgesic in post-operative period for the patients undergoing traumatized lower limb 
orthopaedic surgery. Hence, we have selected the dosage of $10 \mu \mathrm{g}$ of dexmedetomidine with $5 \mathrm{mg}$ of intrathecal bupivacaine in perianal surgeries, as it is saddle block. In our study, there was no significant difference among the groups regarding the age, height, weight and sex of the patients.

In our study, the mean time taken for the onset of the sensory block was $6.36 \pm 1.2$ with group $\mathrm{D}$ and with group $\mathrm{N}$ $8.23 \pm 1.7 \mathrm{~min}$ respectively. Statistically, there was a highly significant shorter onset time of sensory blockage in group D as compared to group $\mathrm{N}(\mathrm{P}<0.001)$. Our study compares with the study conducted by Kanazi et al. ${ }^{6}$ who also have found statistically significant difference in the mean onset of sensory block between group D and group C $8.6 \pm 3.7$ and $8.6 \pm 4.4$ min respectively. Our study compares with the study conducted by AL-Mustafa MM et al, ${ }^{8}$ Halder $\mathrm{S}$ et al,7 who also have found statistically significant difference in mean onset of sensory block between dexmedetomidine group and bupivacaine group.

In our study, the mean duration of analgesia in groups $360 \pm 15$ min and $210 \pm 30$ min with group D and C respectively. There was significant difference between two groups with prolonged duration of post-operative analgesia with group D compared to group N. We could compare our study with Gupta $\mathrm{M}$ et al. ${ }^{9}$ The duration of analgesia was $306.17 \pm 24.34,396.5 \pm 35.60,512.0 \pm 23.55$; in group D $2.5 \mu \mathrm{g}$, group D $5 \mu \mathrm{g}$, group D $10 \mu \mathrm{g}$ respectively. There was significantly prolongation of duration of analgesia depending on the dosage. We could also compare our study with Halder S et al. ${ }^{7}$ The duration of analgesia was group D5 $227.0 \pm 19.85$ and group D10 241.8 \pm 42.10 respectively, which was prolonged with group D10, which was statistically significant.

We could also compare our study with Gupta R et al,4 the duration of analgesia was $478.4 \pm 20.9 \mathrm{~min}$ with group $\mathrm{D}$ and $241.67 \pm 21.67$ min with group $\mathrm{R}$, which was statistically significant with group D, but they have used Ropivacaine instead of bupivacaine. The duration of sensory block and post-operative analgesia were prolonged, so this was comparable to the results of the study conducted by Abdelhamid SA et al, ${ }^{10} \mathrm{Kim}$ JE et al,11 and Eid HEA. ${ }^{12}$

In our study, there was no statistical significance in motor block among the group. In our study, the mean sedation score was assessed using Ramsay sedation scale. There was no statistical significant difference among the groups. In our study, there was no statistically significant difference in the haemodynamic parameters like Heart rate, Systolic blood pressure, Diastolic blood pressure, Mean arterial blood pressure throughout the surgery among the groups. In our study, there was no statistically significant difference in the adverse effects like Bradycardia, Hypotension, Nausea, Vomiting throughout the procedure among the groups.

\section{CONCLUSION}

On the basis of our study, we conclude that addition of dexmedetomidine to hyperbaric bupivacaine intrathecally produces a rapid onset of sensory block and prolongs the postoperative analgesia and the time to first analgesic requirement significantly together with stable haemodynamic parameters and minimal side effects. Dexmedetomidine seems to be an attractive adjuvant to spinal bupivacaine, especially in the perianal surgeries.

\section{REFERENCES}

1. Grewal A. Dexmedetomidine-new avenues. Journal of Anaesth Clin Pharm 2011;27(3):297-300.

2. Berde CB, Strichartz GR. Local anaesthetics. In: Miller RD, Cohen NH, Eriksson LI, Fleisher LA, Weiner-Kronish JP, Young WL, eds. Miller's anaesthesia. Philadelphia: Elsevier Saunders 8thedn, 2015;Vol. 1:P.1205-1234.

3. Gudaityte J, Marchertiene I, Dainius P. Anaesthesia for ambulatory anorectal surgery. Medicina 2004;40(2):101-111.

4. Gupta R, Verma R, BograJ, et al. A comparative study of intrathecal dexmedetomidine and fentanyl as adjuvant. Journal of Anaesthesiol Clinical Pharmacolol 2011;27(3):339-43.

5. Al-Ghanem SM, Massad IM, Al-Mustafa MM, et al. Effect of adding dexmedetomidine versus fentanyl to intrathecal bupivacaine on spinal block characteristics in gynaecological procedure: a double blind controlled study. American Journal of Applied Science 2009;6(5):882-7.

6. Kanazi GE, Aouad MT, Jabbour-Khoury SI, et al. Effect of low dose dexmedetomidine or clonidine on the characteristic of bupivacaine spinal block. Acta Anaesthesiol scand 2006;50(2):222-227.

7. Halder S, Das A, Mandal D. Effect of different doses of dexmedetomidine as adjuvant in bupivacaine induced subarachnoid block for traumatized lower limb orthopaedic surgery: a prospective, double -blinded and randomized controlled study. Journal of Clinical and Diagnostic Research 2014;8(11).

8. Al-Mustafa MM, Abu-Halaweh SA, Aloweidi AS, et al. Effect of dexmedetomidine added to spinal bupivacaine for urological procedure. Saudi Med J 2009;30(3):36570.

9. Gupta M, Gupta P, Singh DK. Effect of 3 different doses of intrathecal dexmedetomidine $(2.5 \mu \mathrm{g}, 5 \mu \mathrm{g}$, AND $10 \mu \mathrm{g})$ on subarachnoid block characteristics: a prospective randomized double blind dose-response trail. Pain Physician 2016;19(3):E411-420.

10. Abdelhamid SA, El-lakany $\mathrm{MH}$. Intrathecal dexmedetomidine: useful or not? J Anaesth Clin Res 2013;4:351.

11. Kim JE, Kim NY, Lee HS, et al. Effect of intrathecal dexmedetomidine on low-dose bupivacaine spinal anaesthesia in elderly patients undergoing transurethral prostatectomy. Biol Pharm Bull 2013;36(6):959-965.

12. Eid HEA, Shafie MA, Youssef HD. Related prolongation of hyperbaric bupivacaine spinal anaesthesia by dexmedetomidine. Ain Shams Journal of Anaesthesiology 2011;4(2):83-95. 